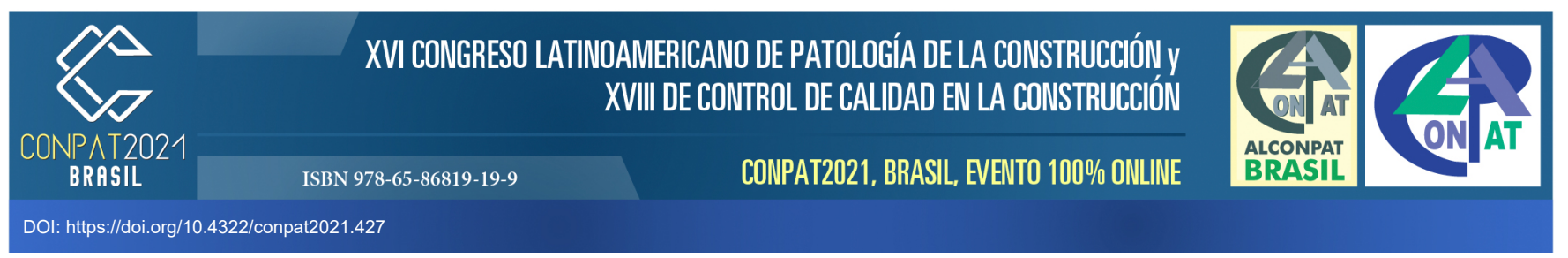

\title{
Planejamento estratégico para restauro e reparo em esquadrias de madeira de patrimônio histórico
}

\author{
J T. Ferreira $^{1 *} ;$ M T. Barbosa ${ }^{1}$ \\ *Autor de contato: jonas.ferreira@arquitetura.ufjf.br \\ 1 Programa de Pós-graduação em Ambiente Construído. Faculdade de Engenharia.Universidade \\ Federal de Juiz de Fora. Juiz de Fora. Brasil
}

\begin{abstract}
RESUMO
Problemas decorrentes de mau uso e/ ou intempéries resulta em danos que comprometem a integridade das edificações. O presente trabalho pretende realizar um levantamento qualitativo e quantitativo das manifestações patológicas nas esquadrias de madeira do Centro Cultural Bernardo Mascarenhas, localizado na cidade de Juiz de Fora (MG) bem como, apresenta estratégias de intervenção. Para tanto, será realizada uma revisão bibliográfica qualitativa sobre o significado da moldura de madeira para o patrimônio histórico, o diagnóstico das anomalias neste componente construtivo. Por fim, a matriz de priorização do GUT (gravidade, urgência e tendência) foi utilizada para o desenvolvimento da estratégia de intervenção. A solução proposta neste trabalho contribui para o fortalecimento de procedimentos simplificados que correlacionam danos e causas com medidas corretivas.
\end{abstract}

Palavras chaves: esquadrias em madeiras; manifestações patológicas; reabilitação; edificações históricas.

\section{RESUMEM}

Los problemas que surgen por el mal uso y / o el clima dan como resultado daños que comprometen la integridad de los edificios. El presente trabajo pretende realizar un relevamiento cualitativo y cuantitativo de las manifestaciones patológicas en los marcos de madera del Centro Cultural Bernardo Mascarenhas, ubicado en la ciudad de Juiz de Fora (MG), además de presentar estrategias 
de intervención. Para ello, se realizará una revisión bibliográfica cualitativa sobre el significado del marco de madera para el patrimonio histórico, el diagnóstico de anomalías en este componente constructivo. Finalmente, se utilizó la matriz de priorización GUT (gravedad, urgencia y tendencia) para desarrollar la estrategia de intervención. La solución propuesta en este trabajo contribuye al fortalecimiento de procedimientos simplificados que correlacionan daños y causas con medidas correctivas.

Contraseñas: marcos de madeira; manifestaciones patológicas; rehabilitación; edificios históricos.

\section{ABSTRACT}

Problems resulting from misuse and / or weather results in damage that compromises the integrity of the buildings. The present work intends to carry out a qualitative and quantitative survey of the pathological manifestations in the wooden frames of the Bernardo Mascarenhas Cultural Center, located in the city of Juiz de Fora (MG), as well as presenting intervention strategies. To this end, a qualitative bibliographic review will be carried out on the meaning of the wooden frame for the historical heritage, the diagnosis of anomalies in this constructive component. Finally, the GUT prioritization matrix (gravity, urgency and tendency) was used to develop the intervention strategy. The solution proposed in this work contributes to the strengthening of simplified procedures that correlate damages and causes with corrective measures.

Keywords: wooden frames; pathological manifestations; rehabilitation; historic buildings.

\section{INTRODUÇÃO}

A manutenção da integridade das edificações históricas, bem como sua conservação é legitimada por diversos autores, como por exemplo, Feilden (1994); Lorenzetti (2010); Saviz, Luc e Saeed (2020) que exaltam seus valores arquitetônicos, estéticos, sociais, políticos, simbólicos, dentre outros. Entretanto, deve-se considerar as alterações climáticas ocorridas nas últimas décadas que tendem a comprometer a vida útil e a durabilidade dos materiais e componentes das edificações, principalmente, as históricas onde os danos são mais significativo devido ao estado insatisfatório de conservação (Walsh, 2012; Philipson, Emmanuel e Baker, 2016).

Mühlbauer e Razeira (2003) destacam o emprego da madeira como material de construção, destacando sua abundância e variedade, tanto na natureza quanto nas obras de arquitetura e engenharia e, com o aprimoramento tecnológico o seu emprego tornou-se mais nobre na fabricação, por exemplo, de esquadrias.

Deve-se considerar, inclusive, a capacidade de renovação que a madeira possui, o que fortalece o seu valor incomparável com as demais fontes de matéria-prima empregadas na indústria da construção civil, já que é uma fonte de recursos renovável (CUNHA, 2011). Sendo assim é empregada há anos como esquadrias nas edificações considerando fatores econômicos (médio e longo prazo), culturais e técnicos. As esquadrias (portas e janelas) são componentes das edificações que interligam os espaços e as pessoas e protege o ambiente interno seja do calor ou frio, seja de ruídos, chuva ou vento e, para as janelas acrescenta-se, também, a função de ventilação e iluminação natural (MIOTTO, 2002; MARQUES; KOJIMA E TOMA, 2014). A tipologia, proporções e quantidades das janelas de madeira empregadas nas construções brasileiras desde o 
seu descobrimento estão correlacionadas às condições culturais e econômicas, bem como ao avanço tecnológico.

De acordo com Marques; Kojima e Toma (2014) “as esquadrais fazem parte da edificação como um elemento simbólico-funcional, mas que possuem também um valor plástico/artístico muito forte, agregando às residências uma linguagem artística e arquitetônica própria do período e da época que foram construídas". Nesse contexto, é natural que à medida em que envelhecem, os materiais das edificações poderão surgir falhas e/ou defeitos, e/ou anomalias (IDRUS; KHMAMIDI; SODANGI, 2010). Desta forma, todos os edifícios, novos ou antigos, requerem planejamento que sejam capazes de limitar sua deterioração; entretanto, no caso dos edifícios históricos, a principal diferença consiste na impossibilidade de substituição de elementos devido a questões de autenticidade e de valor histórico (BARBOSA; SILVA e COURA, 2017).

Os princípios para a intervenção em edificações históricas são universais e estão contidos nas diversas cartas patrimoniais. No que concerne aos elementos de madeira, o ICOMOS (1999) publicou os "Princípios para a Conservação de Estruturas Históricas de Madeira" sendo destacado, resumidamente, na preservação desse material: o reconhecimento da sua importância histórica; a variabilidade de espécies e, consequentemente da qualidade do produto o que o torna vulnerável com o tempo; a escassez, na atualidade, de estruturas históricas em madeira; domínio de ações para preservação desse recurso e, finalmente, o reconhecimento e a obediência às cartas patrimoniais (Carta de Veneza e Carta de Burra) e as doutrinas afins (UNESCO e ICOMOS) nos serviços de restauração e reparo, ou seja, deve-se assegurar a autenticidade e a integridade histórica do patrimônio cultural.

Segundo Lorenzetti (2010) as esquadrias de madeira localizadas nas fachadas externas, estão expostas a agentes abióticos e biológicos causadores de diversas anomalias, destacando, ainda, que as principais causas de degradação nas esquadrias de madeira são os ataques de xilófagos, má conservação da pintura e a insolação que provoca o avançado estado de degradação e ressecamento da madeira.

Segundo PARMA; ICIMOTO (2018) os agentes bióticos são organismos, como fungos e insetos, que alimentam e degradam o material estando as manifestações patológicas associadas a falta de conhecimento do material e de tratamento prévio da madeira. Brito (2014) menciona, também, as degradações originárias de fatores estruturais decorrentes de: remoção de elementos estruturais, fraturas incipientes, deformações e flechas, dentre outros.

Nesse contexto, o presente trabalho visa estabelecer o conceito de degradação das estruturas de madeira presentes nas construções históricas, mas especificadamente, nas esquadrias do Centro Cultural Bernardo Mascaranhas (CCBM), identificando as manifestações patológicas, suas origens, causas bem como, a elaboração de estratégias de intervenção por meio do emprego da ferramenta matriz de priorização GUT, possibilitando, assim, o planejamento da conservação e do reparo do empreendimento.

Segundo Kepner e Tregoe (1997) a matriz de priorização GUT apura os problemas através de três critérios, a saber: Gravidade, Urgência e Tendência, sendo amplamente utilizada no setor empresarial para a definição de prioridades e tomada de decisões. A gravidade é definida como a intensidade, a profundidade do dano que o problema pode causar se não houver intervenção sobre ele; a urgência refere-se ao tempo para que se tenha resultados indesejáveis caso não ocorra nenhum tipo de intervenção e, por fim, a tendência é a desenvolvimento que o problema na ausência de ação. Portanto, o cálculo de GUT (= G x U x T) indica a maior ou menor prioridade para uma dada demanda.

Sendo assim, o presente trabalho é dividido em três etapas: o levantamento qualitativo sobre as manifestações patológicas nas esquadrias de madeira localizadas no CCBM; o diagnóstico das anomalias identificando as causas e a análise quantitativa das anomalias, com auxílio do método GUT. 


\section{ESTUDO DE CASO: CENTRO CULTURAL BERNARDO MASCARANHAS (CCBM)}

De acordo com Moratori e Paiva (2016, p.01) "atual Núcleo Histórico e Arquitetônico Complexo Mascarenhas teve sua origem em 1888, como sede da Companhia Têxtil Bernardo Mascarenhas, sendo a primeira industria a utilizar energia elétrica, contribuindo no reconhecimento da cidade de Juiz de Fora, fundada em 1850, como Manchester Mineira”, vide Figuras 1 e 2.

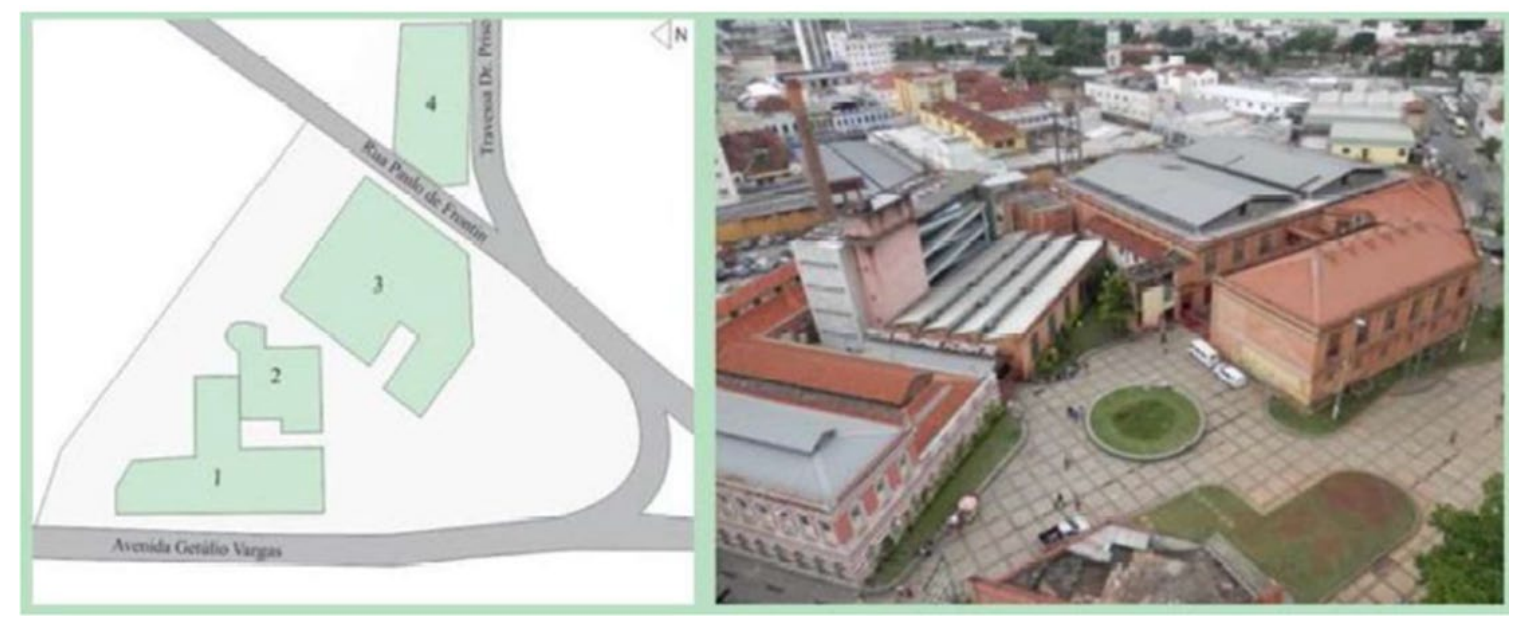

Figura 1. Complexo CCBM. Fonte: Moratori, Paiva e Barbosa (2016).

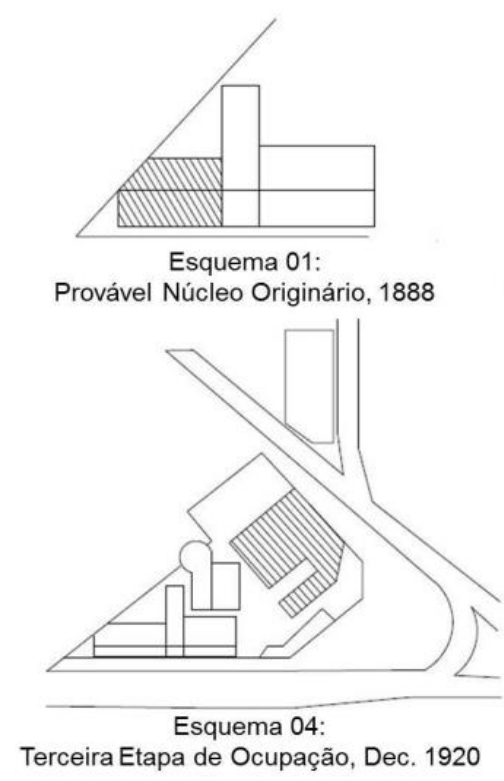

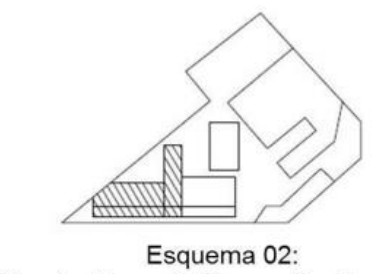

Primeira Etapa de Ocupação, Dec.. 1890

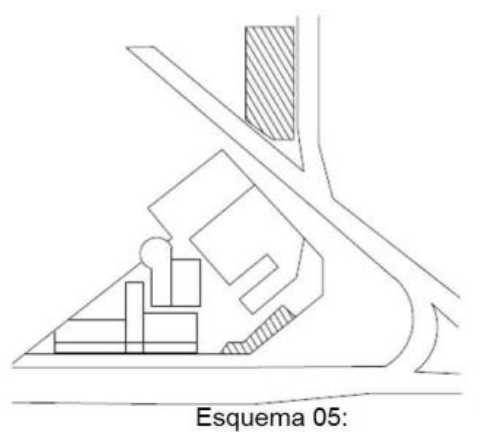

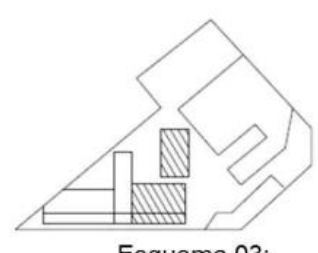

Esquema 03:

Segunda Etapa de Ocupação, Dec.. 1900

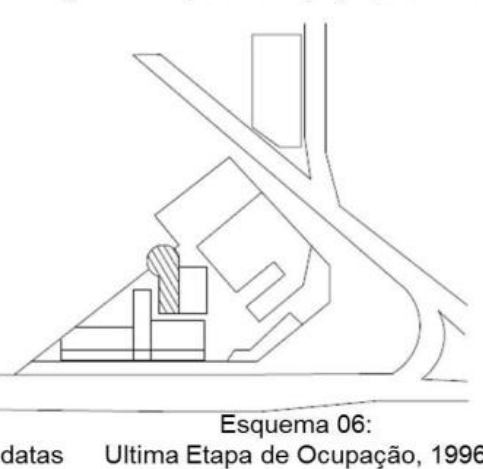

Figura 2. Esquema de intervenções no CCBM. Fonte: Moratori e Paiva (2016).

Segundo Moratori (2016) a simetria do CCBM está embasada em corpo central constituído de três pavimentos, com frontões retos com dupla arcada cega arrematando a composição em suas quatro faces que compõe seu coroamento e marcando o eixo de simetria, ladeado por extensas alas horizontais de dois pavimentos. No térreo abrem-se três vãos de portas, enquanto o segundo nível possui amplas janelas rasgadas por inteiro, com vergas retas, balcões protegidos por grades metálicas apoiadas sobre consoles ornamentados, as fachadas seguem um rítmo regular da 
seqüência de vãos arqueados, com vedações de madeira e vidro, com bandeira fixa, caixilho tipo guilhotina na parte superior e veneziana na inferior.

Todo o conjunto de edifícios tem cerca de $12.498 \mathrm{~m} 2$, sendo que $11.233 \mathrm{~m} 2$ são de área construída e $1.264 \mathrm{~m} 2$ são áreas livres, tais como: estacionamento, áreas de carga e descarga, cívica praças e áreas de circulação. Hoje, o Complexo Cultural Bernardo Mascarenhas (ver Figura 1) é composto por quatro edificações: o Centro Cultural Bernardo Mascarenhas (BMCC) (1); o Mercado Municipal e a Secretaria Municipal de Educação (2); a Biblioteca Municipal Murilo Mendes (3) e Centro de Educação Dr. Geraldo Moutinho de Jovens e Adultos (CEM) (4).

(MORATORI, PAIVA, BARBOSA, 2016 p.196).

\section{METODOLOGIA}

Ao percorrer a edificação, identifica-se diversas anomalias nas janelas, sendo grande parte, fruto da ação das intempéries e da deficiência nos serviços de manutenção. Nesse aspecto destacam-se nas janelas (esquadrias de madeira): avançado estado de degradação decorrente da presença de umidade; vidros quebrados; pequenos reparos com massa em cor destoante aos componentes das esquadrias resultando numa falta de harmonia dos componentes da fachada da edificação.

Diante do exposto, os procedimentos metodológicos são divididos em duas etapas, a saber: qualitativa que consiste no levantamento fotográfico das esquadrias de madeira na fachada Frontal e lateral direita do CCBM, identificando as manifestações patológicas e quantitativa que consiste no no emprego do método GUT, conforme apresentado a seguir:

Primeira etapa: Levantamento das manifestações patológicas nas esquadrias: nesta etapa efetuou-se uma análise visual e um levantamento fotográfico do estado atual das esquadrias de madeira da fachada do CCBM (vide Figura 3), para identificação das anomalias, incluindo suas causas e consequências.

Baseado no levantamento fotográfico e análise visual efetuado nas esquadrias do CCBM, onde identificou-se as causas das manifestações patológicas, o seu grau de criticidade, elaborou-se uma etapa quantitativa de forma a priorizar os reparos e assegurar a savalguarda do patrimônio.

Segunda etapa: Matriz GUT: o método GUT tem como objetivo priorizar as ações de intervenção aos problemas de forma racional, permitindo escolher a tomada de ação menos prejudicial, seguindo as seguintes etapas: listagem dos problemas ou pontos de análise; pontuação de cada tópico; classificação e tomada de decisões estratégicas (SOTILLE, 2014). Sendo assim, atribui-se valores em uma escala de 1 (um) a 5 (cinco) observando critérios de Gravidade, Urgência e Tendência, conforme ilustrado na Tabela 1. 


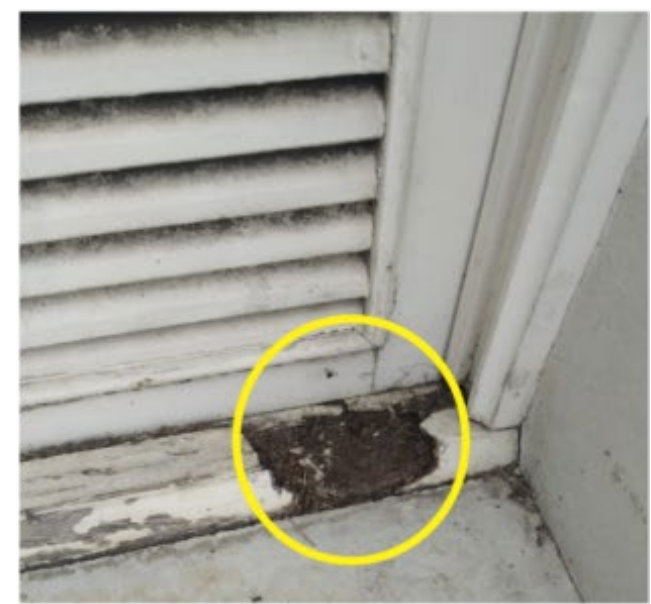

janelas apodrecidas pela umidade

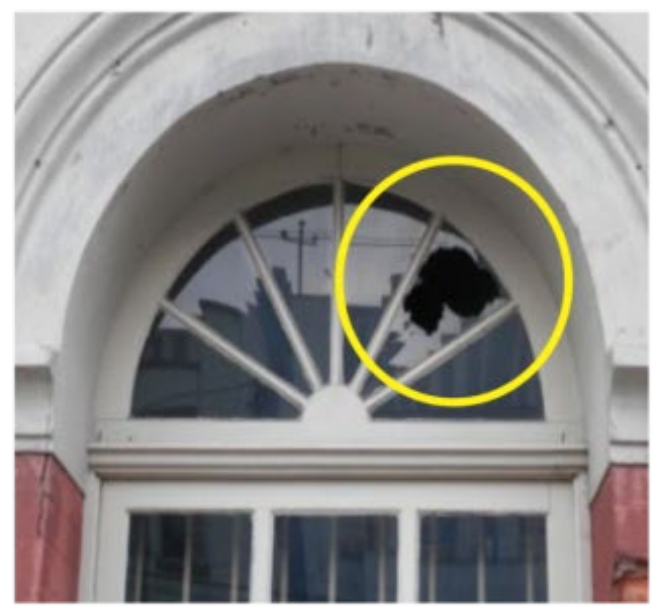

Vidro quebrado origem intreseca e extrinseca

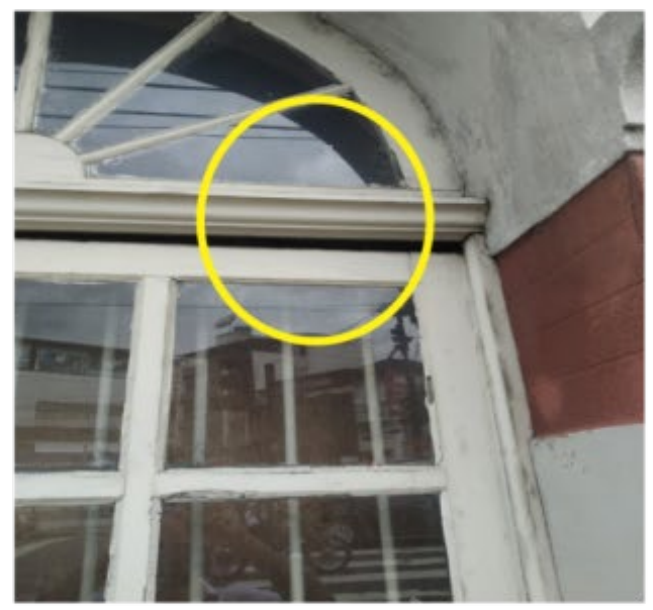

Perda de seção

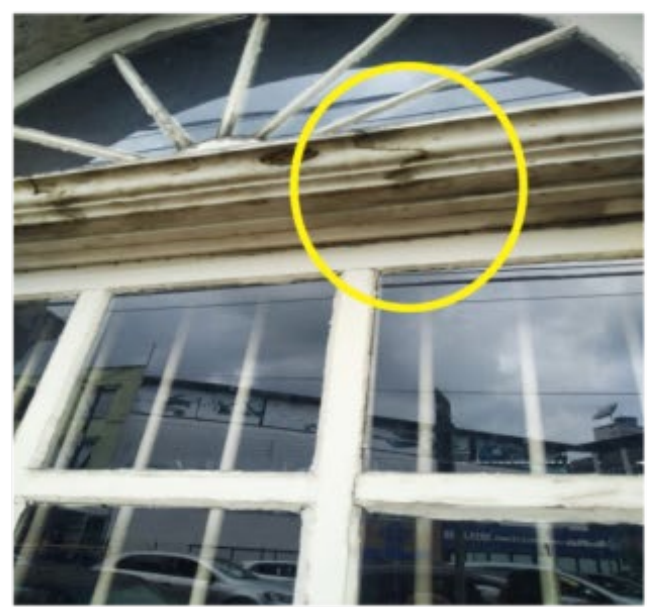

manchamentos por umidade

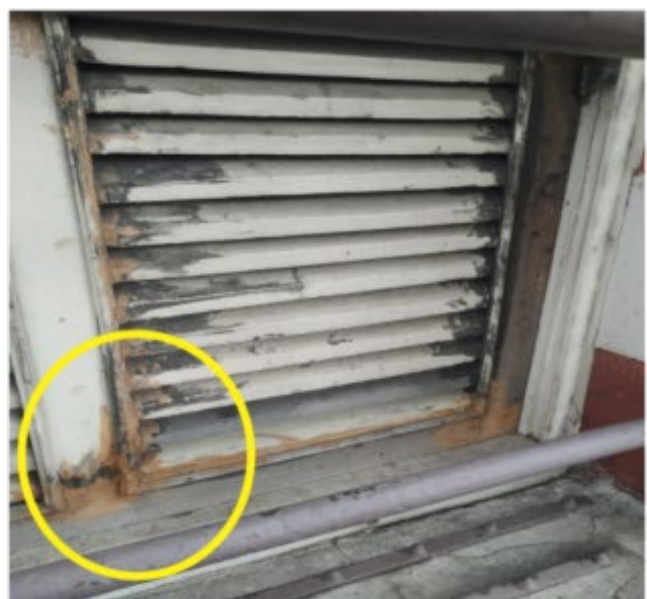

pontos com massa por descupinização ou de colagem da madeira em tons destoantes

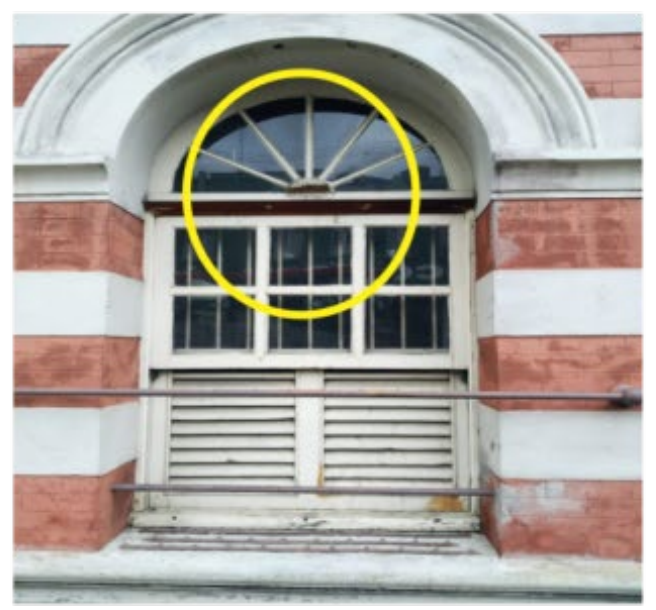

substituição de estrutura destoante

Figura 3. Levantamento fotográfico das patologias nas esquadrias do CCBM. 
Tabela 1. Critérios da Metodologia GUT. Fonte: adaptado Aldo et al (2020).

\begin{tabular}{|c|c|c|c|}
\hline Pontos & Gravidade & Urgência & Tendência \\
\hline Definições & $\begin{array}{c}\text { É a intensidade de } \\
\text { danos que pode } \\
\text { ocorrer caso não } \\
\text { ocorram } \\
\text { intervenção }\end{array}$ & $\begin{array}{c}\text { Tempo estimado } \\
\text { para a resolução } \\
\text { de uma } \\
\text { determinada } \\
\text { situação }\end{array}$ & $\begin{array}{c}\text { Padrão evolutivo, } \\
\text { quando ausente } \\
\text { ação }\end{array}$ \\
\hline 5 & $\begin{array}{c}\text { Extremamente } \\
\text { grave }\end{array}$ & Imediatamente & $\begin{array}{c}\text { Piora muito ou, } \\
\text { rapidamente. }\end{array}$ \\
\hline 4 & Muito grave & Curto prazo & $\begin{array}{c}\text { Aumenta ou piora } \\
\text { em pouco tempo }\end{array}$ \\
\hline 3 & Grave & Prazo médio & $\begin{array}{c}\text { Permanece igual } \\
\text { ou piora em médio } \\
\text { prazo }\end{array}$ \\
\hline 2 & Pouco grave & Longo prazo & $\begin{array}{c}\text { Reduz ou piora } \\
\text { em longo prazo }\end{array}$ \\
\hline 1 & Sem gravidade & Longuíssimo prazo & $\begin{array}{c}\text { Desaparece ou } \\
\text { não piora }\end{array}$ \\
\hline
\end{tabular}

\section{RESULTADOS E ANÁLISES}

A Tabela 2 apresenta os resultados obtidos no levantamnto efetuado, incluindo aos resultados obtidos com o emprego do método GUT, sendo possível verificar:

Tabela 2. Levantamento das manifestações patológicas nas esquadrias externas (fachada) e método GUT

\begin{tabular}{|c|c|c|c|c|c|}
\hline \multirow{2}{*}{$\begin{array}{l}\text { Manifestações } \\
\text { Patológicas }\end{array}$} & \multirow[t]{2}{*}{ Causas prováveis } & \multicolumn{3}{|c|}{ MÉTODOGUT } & \multirow[t]{2}{*}{ Total } \\
\hline & & G & $\mathbf{U}$ & $\mathbf{T}$ & \\
\hline Apodrecimento & $\begin{array}{l}\text { Ação do intemperismo asscoiada a } \\
\text { prsença de umidade, microrganismos } \\
\text { e insetos. }\end{array}$ & 5 & 3 & 4 & 50 \\
\hline Manchamentos & $\begin{array}{l}\text { Percolação e penetração de água } \\
\text { decorrente de falhas no sistema de } \\
\text { proteção (pintura) }\end{array}$ & 3 & 2 & 3 & 18 \\
\hline Pigmentação & $\begin{array}{l}\text { Pequenos reparos efetuados com } \\
\text { massa inapropriada. }\end{array}$ & 2 & 3 & 1 & 6 \\
\hline Falta de seção & $\begin{array}{l}\text { Instabilidade do componente devido a } \\
\text { ações físicas e/ou mecânicas e/ou } \\
\text { higrotérmica. }\end{array}$ & 1 & 2 & 2 & 4 \\
\hline $\begin{array}{l}\text { Heterogeneidade } \\
\text { do material }\end{array}$ & $\begin{array}{l}\text { Deterioração da madeira e/ou perda } \\
\text { do componente original. }\end{array}$ & 1 & 2 & 4 & 8 \\
\hline
\end{tabular}

i) A deficiência nos serviços de manutenção associada a presença de agentes de degradação (intempreismo, físicos, químicos, biológicos) em muito contribuíram para o elevado grau 
de deterioração do componente construtivo. Deve-se considerar que uma medida protetiva e preventiva consiste no emprego de produtos que dificultam o acesso, principalmente, da umidade à madeira, como o caso das tintas já que são capazes de penetrar no material (madeira) formando uma película externa protetora e impermeável. Sendo assim, para as peças comprometidas recomenda-se serviços de restauro com recuperação ou substituição da área comprometida;

ii) Os mancahmentos presentes, causados pela presença de umidade e desenvolvimento de microorganismos (fungos, por exemplo) são resultado da falta de seviços de manutenção, ou seja, repintura. Essa anamolia tende a reduzir sua dureza do material em até $10 \%$, a resistência à flexão em até $5 \%$ e ao impacto em até 30\%. (RHODMANN, 2021), comprometendo a vida útil do componenete. Para o tratamento dessa anomalia empregase produtos químcos que elimine os fungos, se a umidade não tiver penetrado até o cerne podem ser indicados o tratamento com lixamento e escovação;

iii) Os pequenos reparos efetuados até o momento, devido a falhas no material (perda de material por ataque, por exemplo, insetos, impactos, dentre outros) que resultaram num aspecto estético desuniforme bem como, proporcionam uma resistência mecânica heterogênea no componente, já que ora empregou-se material de recomposição de qualidade inferior ao original, ora superior. Sendo assim, destaca-se a importância do emprego de peças de recomposição de mesma origem, devendo-se substituir por novas peças de acordo com molde para evitar problemas de encaixe nas seções. Deve-se considerar, inclusive o emprego de massa para corrigir as imperfeições causadas por insetos, sendo necessário, também, a descupinização ou colagem da estrutura de madeira das esquadrias, no levantamento fotográfico realizado foi identificados que esses pontos com massa nas estruturas não receberam nenhum acabamento, dessa forma apresentaram um aspecto destoante da madeira prejudicando a estética das esquadrias. Para solucionar esses problemas, devem primeiramente fazer o trabalho de descupinização por seringa na madeira através da injeção de produtos como inseticidas e dedetizadores, para aplicação de massas primeiramente deve retirar as partes comprometidas e fazer a modelagem e a colagem de acordo com formato das seções, depois da secagem das massas deve-se fazer o lixamento para eliminar excessos do produto, e por fim pintar as peças com a cor original do madeiramento para não destoar da estrutura original;

iv) A Falta de seção no componente são resultado das degradações físico-química, biológicas e estrutural sendo, portanto, necessário a proteção e monitoramento contra os agentes biológicos, para evitar possíveis deteriorações, para as degradações deve-se auxiliar de uma equipe técnica que possa a interferir de forma correta sobre a substituição e reposição das partes comprometidas;

\section{CONCLUSÃO}

A manutenção nas estruturas de madeiras para a detectação e patologias geralmente é um processo mais racional e não custoso, deve incluir procedimentos periódicos de inspeção. Com isso as patologias que ocorrem na madeira podem ser minimizadas ou até evitadas se houver inspeção preventiva. A partir da inspeção é possível identificar alterações no material e qualificar os agentes envolvidos nas deteriorações.

O método GUT usado no estudo foi muito importante para determinar as prioridades de intervenção de acordo com as causas das patologias registradas pelo levantamento fotográfico.

Através do estudo constatou-se que a inspeção periodicamente da madeira pode maximizar a vida útil e minimizar os custos com reparos, detectando os tipos de anomalias para propor um tratamento mais simples e de custo menor. 
$\mathrm{O}$ tratamento confere durabilidade e longevidade à madeira. O tipo de tratamento é definido de acordo com o ambiente em que a madeira ficará exposta.

Sendo assim foram encontradas manifestações patológicas como o avançado estado de degradação da madeira, manchamentos, pontos com massa, perda de seção e substituição de estrutura destoante.

Estima-se que as principais causas são a Interferência de condições naturais: temperatura Umidade e oxigênio, espécie da madeira, microrganismo e insetos, Presença de umidade na madeira através da penetração de água, defeito, falha de execução, vida útil, processos naturais, agentes externos, intempéries e ação do homem, descupinização ou colagem da madeira.

Espera-se que esse trabalho possa contribuir para um melhor entendimento das causas patológicas nas esquadrias do de madeira e que as ações de restaurações possa ser inseridas no contexto correto para que as intervenções no patrimônio histórico seja eleboradas com estratégias aplicáveis e eficiêntes na reabilitação do conjunto arquitetônico que se alinhem com os objetivos dessa causa, identificando as ações que não estão sendo desenvolvidas e comprometam as diretrizes derestauração e reparo.

\section{AGRADECIMENTOS}

CNPQ - Conselho Nacional de Desenvolvimento Científico e Tecnológico - Brasil

CAPES - Coordenação de Aperfeiçoamento de Pessoal de Nível Superior

\section{REFERÊNCIAS BIBLIOGRÁFICAS}

Almeida, F. A. L. (2012). A madeira como material estrutural - Projeto da estrutura da cobertura de um edifício. 310 f. Dissertação (Mestre em Engenharia Civil) - Departamento de Engenharia Civil, Faculdade de Engenharia da Universidade do Porto. Porto. Portugal.

Araújo, R. T. (2012) Alternativas sustentáveis do uso da madeira na construção civil. Especialize. n.4, p. 115.

Barbosa, M T; Silva, B; Coura, C. (2017). A importância dos serviços de manutenção no patrimônio histórico. Cine Theatro Central, Palacete Santa Mafalda e Fórum da Cultura em Juiz de Fora. Arquitextos, São Paulo, ano 18, n. 205.04, Vitruvius, jun.

Braga, M; Razeira, P; Mühlbauer, C.F. (2003). Conservação e restauração de madeira na arquitetura brasileira. In: Marcia Braga. (Org.). Conservação e restauro. Rio de Janeiro: Editora Rio, v., p. 9-50.

Brito L. D. (2014). Patologia em Estruturas de Madeira: Metodologia de Inspeção e Técnicas de Reabilitação. 502 f. Tese (Doutorado em Engenharia de Estruturas) - Departamento de Engenharia de Estruturas, Escola de Engenharia de São Carlos, Universidade de São Paulo. São Carlos.

Calil JR, C. et al. (2006) . Manual de projeto e construção de pontes de Madeira. $237 \mathrm{f}$. Departamento de Engenharia das Estruturas, Escola de Engenharia de São Carlos, Universidade de São Paulo. São Carlos.

Carvalho, A; Silva, I. ; Rosse, V.; Barbosa, M T. (2020). O emprego do Método GUT na solução de manifestações patológicas no Instituto Maria. In: V Congrsso Internacional de recuperação, manuntenção e reabilitação, 2020, Rio de Janeiro - Virtual. V Cirmare.

Cunha, V. (2011). Madeira e sustentabilidade, como vai esta relação?. Arquitextos, n.11. 
Feilden, B. (1994). Conservation Historic Buildings. Oxford: Butterworth Architecture.

ICOMOS (1999). Princípios para a preservação das estruturas históricas em madeira. Disponível em: https://5cidade.files.wordpress.com/2008/03/principios-para-a-preservacao-das-estruturashistoricas-em-madeira.pdf, acessado em 21 de fev/2021.

Idrus, A.; Khmamidi, F.; Sodangi, M. (2010). Maintenance Management Framework for Conservation of Heritage Buildings in Malasya. Modern Applied Science. Vol. 04, n.11.

Kepner, C; Tregoe, B. (1997). The new rational manger. Pinceton Research Press.

Lorenzetti, E.T. (2010). Análise das técnicas de intervenção em esquadrias de madeira e nos revestimentos argamassados da fachada de tres edificações históricas do século XIX e XX no estado do Paraná, sob o enfoque tecnológico e dos critérios de conservação patrimonias. 2010. 180 f. Dissertação (Mestrado em Arquitetura e Urbanismo) universidade Federal de Santa Catarina, Florianopolis.

Manchas na madeira. Rhodmann. Mercês, Curitiba PR, Disponível em: https://www.rhodmann.com.br/2018/06/manchas-na-madeira/. Acesso 24 Fev. de 2021.

Marques, C.C.G; Kojima, J.S; Toma, M.Y.(2014). Casas de madeira de Londrina: Á importancia das esquadrias. Revista terra e cultura, Ano 30, Centro Universitário Filadélfia, Londrina, Paraná.

MilanI, C. J; Kripka, M. (2021). A identificação de patologias em pontes de madeira: diagnóstico realizado no sistema viário do município de Pato Branco - Paraná. 11 f. Anais In: REEC - Revista Eletrônica de Engenharia Civil. Disponível em: https://www.revistas.ufg.br/index.php/index. Acesso em: 19 Jan. 2021.

Miotto, J. L.(2002). A evolução das esquadrias de madeira no Brasil. UNOPAR Cient., Ciênc. Exatas Tecno. Londrina, v. 1, n. 1, p. 55-62.

Moratori, D. A. (2016). Centro Cultural Bernardo Mascarenhas: Reabilitação, desenvolvimento sustentável e educação patrimonial. In: VIII MESTRES E CONSELHEIROS: Agentes Multiplicadores do Patrimônio - Os Desafios do Patrimônio Imaterial, 2016, Belo Horizonte, MG. Anais do $8^{\circ}$ Forum Mestres e Conselheiros: Agentes Multiplicadores do Patrimônio - Os Desafios do Patrimônio Imaterial. Belo Horizonte. p. 1-16.

Moratori, D. A.; Barbosa, M. T. G. (2016). Análise da reabilitação do Centro Cultural Bernardo Mascarenhas baseado nos critérios do Desenvolvimento Sustentável. In: $2^{\circ}$ Congresso Brasileiro de Patologia das Construções, 2016, Belém, PA. Anais do $2^{\circ}$ Congresso Brasileiro de Patologia das Construções. São Leopoldo: Casa leiria, 2016. p. 149-157.

Moratori, D. A.; Paiva, C. R. (2016). Paisagem Cultural e Patrimônio Industrial: Processo de salvaguarda de núcleo historico arquitetônico do século XIX em Juiz de Fora/MG. In: $4^{\circ}$ Colóquio Ibero-americano Paisagem cultural, patrimônio e projeto: Desafios e perspectivas, 2016, Belo Horizonte. Anais do $4^{\circ}$ Colóquio Ibero-americano Paisagem cultural, patrimônio e projeto: Desafios e perspectivas.

Moratori, D. A.; Paiva, C. R.; Barbosa, M. T. G. (2016). Analysis of rehabilitation of the Centro Cultural Bernardo Mascaranhas considering the concept of sustainable development. In: SBE16 Brazil \& Portugal - Sustainable Urban Communities towards a Nearly Zero Impact Built Environment, 2016, Vitória - Espirito Santo. Anais do SBE16 Brazil \& Portugal - Sustainable Urban Communities towards a Nearly Zero Impact Built Environment, 2016. v. 1. p. 295-304. 
Neves, D.R.R. (2009). Estratégia de Inspeção Predial. P. 12-19. Dissertação (Mestrado em Construção Civil) - Universidade Fundação Municipal para Educação Comunitária, Belo Horizonte.

Parma, A.P; Icimoto, F.H. (2018). Patologias em Estruturas de Madeira ocasionadas por agentes bióticos e abióticos. Revista Científica Semana Acadêmica. Fortaleza, ano MMXVIII, N ${ }^{\circ}$. $000141,14 / 11 / 2018$.

Phillipson; Emmanuel; Baker. (2016). The durability of building materials under a changing climate. WIREs, Clim Change.. 590-599. DOI: 10.1002/wcc.398.

Saviz, M; Luc, C; Saeed, M. (2020). Design strategies using multi-criteria decision-making tools to enhance the performance of building façades. Journal of Building Engineering; 30. DOI: 10.1016/j.jobe.2020.101274.

Sotille, M.A. (2014). GUT - Gravidade, Urgência e Tendência. PM Tech Capacitação em Projetos..

Souza, V. C. M.; Ripper, T. (1998). Patologia, recuperação e reforço de estruturas de concreto. Editora Pini. São Paulo.

Walsh, Justin St. P. (2012). Protection of humanity's cultural and historic heritage in space. Space Policy. 28.4, 234-243. DOI: 10.1016/j.spacepol.2012.04.001. 